\title{
Characterization of mesenchymal
} cells beneath cornification of the fetal epithelium and epidermis at the face: an immunohistochemical study using human fetal specimens

\author{
Ji Hyun Kim ${ }^{1}$, Zhe Wu Jin ${ }^{2}$, Gen Murakami ${ }^{3}$, Baik Hwan Cho ${ }^{4,5}$ \\ ${ }^{1}$ Department of Anatomy, Chonbuk National University Medical School, Jeonju, Korea, ${ }^{2}$ Department of Anatomy, Histology and Embryology, Yanbian \\ University Medical College, Yanji, Jilin, China, ${ }^{3}$ Division of Internal Medicine, Iwamizawa Asuka Hospital, Iwamizawa, Japan, ${ }^{4}$ Department of Surgery, \\ Chonbuk National University Hospital, Jeonju, Korea, ${ }^{5}$ Research Institute of Clinical Medicine, Chonbuk National University-Biomedical Research \\ Institute, Chonbuk National University Hospital, Jeonju, Korea
}

\begin{abstract}
Fetal development of the face involves a specific type of cornification in which keratinocytes provide a mass or plug to fill a cavity. The epithelial-mesenchymal interaction was likely to be different from that in the usual skin. We examined expression of intermediate filaments and other mesenchymal markers beneath cornification in the fetal face. Using sections from 5 mid-term human fetuses at 14-16 weeks, immunohistochemistry was conducted for cytokeratins (CK), vimentin, nestin, glial fibrilary acidic protein, desmin, CD34, CD68 and proliferating cell nuclear antigen (PCNA). Fetal zygomatic skin was composed of a thin stratum corneum and a stratum basale (CK5/6+, CK14+, and CK19+) and, as the intermediate layer, 2-3 layered large keratinocytes with nucleus. The basal layer was lined by mono-layered mesenchymal cells (CD34+ and nestin+). Some of basal cells were PCNA-positive. In the keratinocyte plug at the external ear and nose, most cell nuclei expressed PCNA, CK5/6, CK14, and CK19. Vimentin-positive mesenchymal cells migrated into the plug. The PCNA-positive nucleus as well as mesenchymal cell migration was not seen in the lip margin in spite of the thick keratinocyte layer. The lingual epithelium were characterized by the CK7-positive stratum corneum as well as the thick mesenchymal papilla. CD68-positive macrophages were absent in the epidermis/epithelium. Being different from usual cornification of the skin, loss of a mesenchymal monolayer as well as superficial migration of mesenchymal cells might connect with a specific differentiation of keratinocyte to provide a plug at the fetal nose and ear.
\end{abstract}

Key words: Keratinocytes, Cornification, Epithelium, Epidermis, Human fetuses

Received December 17, 2015; 1st Revised January 25, 2016; 2nd Revised February 4, 2016; 3rd Revised February 5, 2016; Accepted February 11, 2016

\section{Corresponding author:}

Baik Hwan Cho

Department of Surgery, Chonbuk National University Hospital, 20 Geonji-ro, Deokjin-gu, Jeonju 54907, Korea

Tel: +82-63-250-1570, Fax:+82-63-271-6197, E-mail: chobh@jbnu.ac.kr

\section{Introduction}

Fetal development of the external nose, ear, and eye involves a temporary plug formation resulting from the increased proliferation of keratinocytes, followed by canalization or recanalization mediated by a specific type of programmed

\section{Copyright (c) 2016. Anatomy \& Cell Biology}

This is an Open Access article distributed under the terms of the Creative Commons Attribution Non-Commercial License (http://creativecommons.org/licenses/by-nc/4.0/) which permits unrestricted non-commercial use, distribution, and reproduction in any medium, provided the original work is properly cited. 
cell death, i.e., cornification [1, 2]. Recanalization of the anterior nose starts at 13 weeks and ends at 17 weeks of gestation [3-5]. Similarly, recanalization of the external auditory meatus starts at 13 weeks and continues until 16.5 weeks of gestation $[6,7]$. Likewise, the excretory tear duct of the eye, consisting of the lacrimal canaliculi, lacrimal sac and nasolacrimal duct, is formed by canalization of the cord-like structure of keratinized epithelial cells $[8,9]$. Canalization through a keratinized epidermal/epithelial tissue is also seen in the fetal perineal region such as the glandular urethra $[10,11]$. In addition, although the embryonic stomodeum maintains its initial opening for the fetal mouth, a significant proliferation of oral and cutaneous keratinocytes is seen along the future lip margins and followed by the destruction to sculpture the upper and lower oral vestibules [3]. In those contexts, we should make clear the difference between the epidermal/epithelial plug and the usual cornification of skin. First, proliferation of keratinocytes continuously advances to fill the cavity or ductal lumen completely. Thus, the thickness of keratinocyte layer is much thicker than the usual skin. Second, according to Masumoto et al. [12], most or all of the keratinocytes most likely to carry cell nucleus in the plugs, in contrast to lost nuclei in the usual cornified layer of skin.

To our knowledge, the morphological difference between the fetal plug and usual skin was not examined immunohistochemistry. We hypothesized that, during a process of the plug formation, basal cells of the epidermis/epithelium may determine the final amount and extent of the keratinocyte mass according to the space of lumen. Therefore, in the present study, we paid attention to mesenchymal cells beneath the epidermis/epithelium. A change in intermediate filaments from cytokeratin $(\mathrm{CK})$ to vimentin seems to be essential for epithelial-mesenchymal transition in normal embryonic development $[13,14]$ as well as cancer metastasis $[15,16]$. In the present study, we used CK5/6, CK7, CK14, and CK19 for the epithelial marker: CK7 and CK19 are characterized by their positivity in the ductal epithelium and these are commonly used as a marker of tumors $[17,18]$. CK5/6 and CK14 are not famous but they are considered to be kinds of maturation markers of the epithelial lining [19, 20]. All types of intermediate filaments seemed to be candidates to determine differentiation of the epidermis/epithelium: (1) vimentin is the most famous marker of mesenchymal tissues (reviewed by Galou et al. [21]); (2) glial fibrilary acidic protein (GFAP) and nestin are well-known markers of developing nerves (reviewed by Shibata et al. [22]). However, GFAP and nestin express also in mesenchymal tissues in and around fetal limb joints [23] and elastic cartilage tissues (reviewed by Katori et al. [24]). (3) Desmin plays a critical role in the initial attachment between striated muscle and tendons [25] and is thought to maintain the stability of mesenchymal cells in association with vimentin, another intermediate filament [26]. In addition, CD34 is a major marker of stromal (mesenchymal) and vascular progenitor cells in both adults and fetuses [27, 28]. However, the dermis and subcutaneous tissue also express CD34 [29-31]. Consequently, we examined expressions of intermediate filaments and other mesenchymal markers beneath cornification in the fetal face.

\section{Materials and Methods}

The study was performed in accordance with the provisions of the Declaration of Helsinki 1995 (as revised in 2013). Semiserial paraffin sections of the head (horizontal; $5 \mu \mathrm{m}$ in thickness; $20-50 \mu \mathrm{m}$ interval) were obtained from 5 mid-term human fetuses at 14-16 weeks (crown-rump length, $100-125 \mathrm{~mm} ; 1$ fetus at 14 weeks; 2 at 15 weeks; 2 at 16 weeks). These specimens were donated by their families to the Department of Anatomy, Yanbian University Medical College, Yanji, China, and their use for research was approved by the university ethics committee in Yanji (No. BS-13-35). These fetuses were obtained by induced abortion, after which the mother was orally informed by an obstetrician at the college teaching hospital of the possibility of donating the fetus for research; no attempt was made to actively encourage the donation. After the mother agreed, the fetus was assigned a specimen number and stored in $10 \% \mathrm{w} / \mathrm{w}$ neutral formalin solution for more than 1 month. Because of specimen number randomization, there was no possibility of contacting the family at a later date. After dividing the body into parts, head samples were decalcified by incubating at $4^{\circ} \mathrm{C}$ in 0.5 mol/L ethylenediaminetetraacetic acid ( $\mathrm{pH} 7.5)$ solution (Decalcifying Solution B, Wako, Tokyo, Japan) for 3-5 days, depending on the size of the sample.

From each of the 5 head specimens, we prepared 150-300 semiserial sections covering the entire face. One of every 5 sections were stained with hematoxylin and eosin to find sections including (1) the skin at the zygomatic or parotid region, (2) the external auditory meatus, (3) external nasal opening, (4) the lateral surface of the tongue, or (5) the putative lower lip or a lower margin of the mouth. After finding the sites, four of every five sections (i.e., unstained 
sections) were used for immunohistochemistry.

The primary antibodies used for immunohistochemistry were (1) mouse monoclonal anti-human cytokeratin (keratin) 5/6 or CK5/6 (M7237, 1:100, Dako, Glostrup, Denmark), (2) mouse monoclonal anti-human cytokeratin 7 or CK7 (1:100, N1626, Dako), (3) mouse monoclonal anti-human cytokeratin 14 or CK14 (1:50, LL002, Novo, Newcastle upon Tyne, UK), (4) mouse monoclonal anti-human cytokeratin 19 or CK19 (sc-6278, 1:100, Santa Cruz Biotechnology, Santa Cruz, CA, USA), (5) mouse monoclonal anti-human vimentin (1:10, M7020, Dako), (6) mouse monoclonal anti-human nestin (sc23927, 1:100, Santa Cruz Biotechnology), (7) rabbit polyclonal anti-human glial fibrilary acidic protein or GFAP (1:100, Z0334, Dako Cytomation, Kyoto, Japan), (8) mouse monoclonal anti-human desmin (1:100, M0760, Dako), (9) mouse monoclonal anti-human CD34 class II (M7165, 1:100, Dako), (10) mouse monoclonal anti-human proliferating cell nuclear antigen or PCNA (0879, Dako, 1:100), and (11) mouse monoclonal anti-human CD68 KP1 (M0814, 1:100, Dako). Autoclave pretreatment was not conducted because of the loose nature of the fetal tissues. The secondary antibody (Dako Chem Mate Envison Kit, Dako) was labeled with horseradish peroxidase (HRP), and antigen-antibody reactions were detected by the HRP-catalyzed reaction with diaminobenzidine. Counterstaining with hematoxylin was performed on the same samples. The negative control without a first antibody was set up for each of the specimens. Observations and taking photographs were usually performed with Nikon Eclipse 80 (Nikon, Tokyo, Japan).

\section{Results}

\section{Observations of hematoxylin and eosin sections}

Fig. 1 displays topographical anatomy in and around the 5 sites examined. The zygomatic skin (Fig. 1A) was composed of (1) a thin but distinct, eosinophilic, homogeneous lamina or the stratum corneum and (2) the basal layer (stratum basale) and, between them, (3) the 2-3 layered keratinocytes as an intermediate layer. In the anterior nose (Fig. 1B, G), the lower lip (Fig. 1E, F) and the external auditory meatus (Fig. $1 \mathrm{H}, \mathrm{I})$, the intermediate, keratinocyte layer was very thick (more than $0.5 \mathrm{~mm}$ at maximum) with a tall basal cell layer. In spite of the thick keratinocyte layer, a surface homogeneous layer or the stratum corneum was thin or unclear in the nose, lip and ear. Notably, in these 3 sites, most of the keratinocytes carried cell nucleus.
In the external ear, the basal cell nuclei were large in the posterolateral aspect surrounded by elastic cartilages, but they were small in the anteromedial aspect continuous to the developing tympanic membrane. Thus, the latter calls appeared to be simple columnar (Fig. 1I). At the lip margin, the keratinocyte layer was very thick and connected with the contralateral side by a thin bridge (Fig. 1E). The lingual epithelium was characterized by abundant, deep protrusions of the basal layer into the internal, mesenchymal tissue (Fig. 1C, D). The epithelial protrusion was similar to the stratum spinosum of the adult skin because of the irregularly-shaped cells packed in a narrow area. No melanin granules were found in any cells at all sites examined.

\section{Observations of immunohistochemistry for CKs}

Basal cells were positive for CK19, CK14, and CK5/6 at the skin, external ear and nose, tongue and lip (Fig. 2). However, the positive cells for CK14 were restricted in the deep protrusion into mesenchymal tissues. Keratinocytes in the plug also usually expressed these 3 CKs, but in basal cells of the plug, positivity of CK19 was weaker than that of CK14 or CK5/6 (Fig. 2B, F, J). Expression of CK7 was seen in epithelia of the upper pharynx and auditory tube as well as the developing salivary glands (Fig. 3A-C). A stratum corneum covering the lingual surface also expressed CK7-positive (Fig. 3C).

\section{Observations of immunohistochemistry for CD68}

CD68-positive macrophages were absent in epidermis and epithelium examined. The macrophages were abundant in the subcutaneous tissue (Fig. 3D) but few in mesenchymal tissues at the ear, nose, tongue and lip (Fig. 3E). The keratinocyte plug contained no macrophages (Fig. 3E).

\section{Observations of immunohistochemistry for vimentin}

In all sites examined, the vimentin-positive mesenchymal tissue was closely located to the basal layer of the epidermis or epithelium (Fig. 4). However, in the external auditory meatus and the lower lip margin, a thin homogeneous lamina, that was vimentin-negative, was evident beneath the basal layer of the epithelium (Fig. 4B, E). However, the lamina was thin and difficult to identify in the other 3 sites (Fig. 4A, C, D). Notably, in the external nasal opening and the external auditory meatus, vimentin-positive mesenchymal cells and their fragments were scattered both in the basal layer and the keratinocyte mass (Fig. 4B, C). 

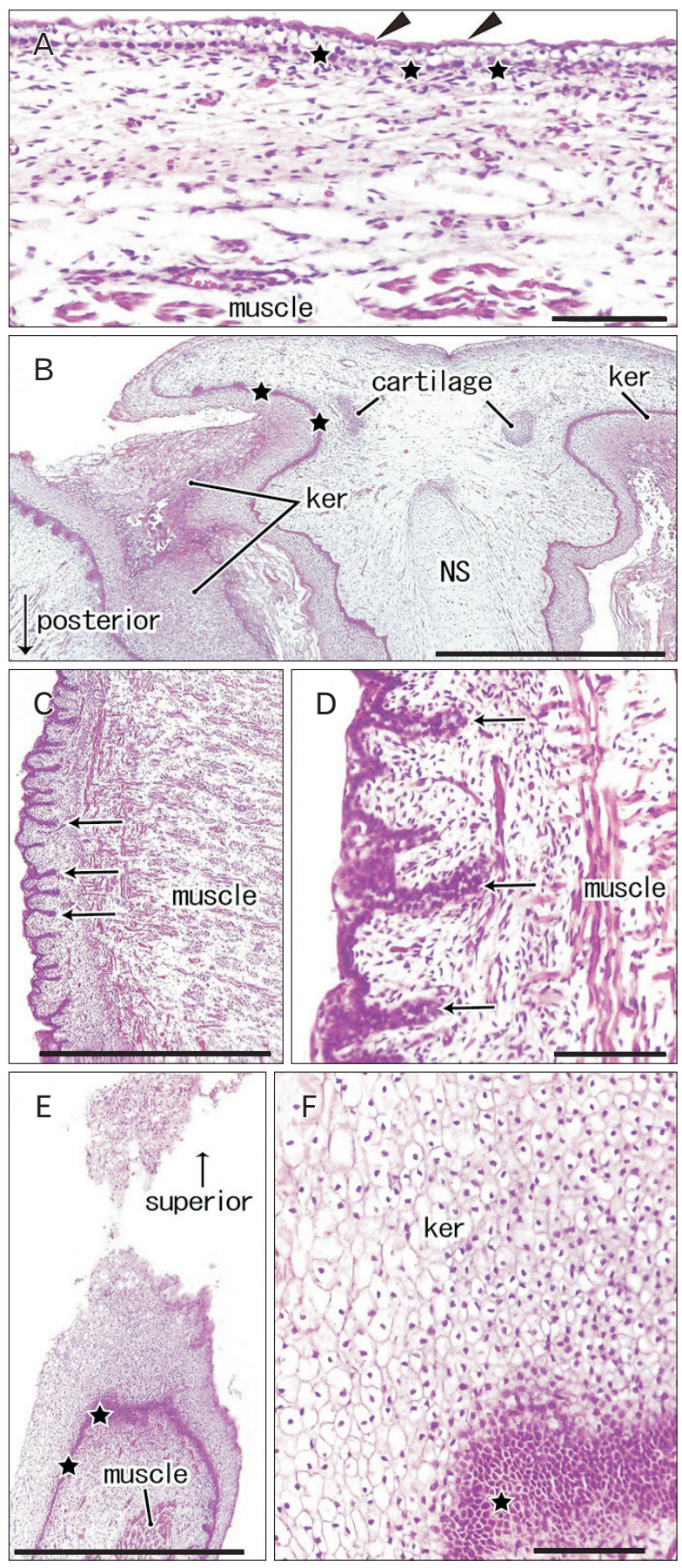

\section{Observations of immunohistochemistry for nestin}

Striated muscles were strongly positive near the zygomatic skin, the external nasal opening, the external auditory meatus and the lingual epithelium (Fig. 4F-I). Nestin-reactivity was also seen in mesenchymal cells and fibers especially near the basal layer: the reactivity was extremely strong around the external meatus as well as beneath the zygomatic skin. Notably, nestin-positive cells took a linear arrangement

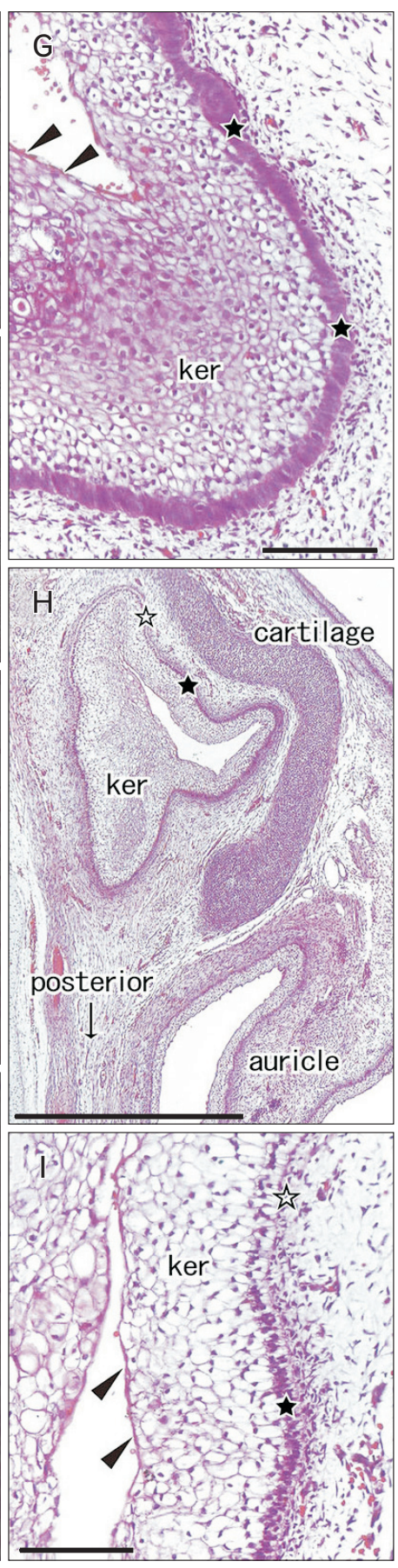

Fig. 1. Hematoxylin and eosin staining histology of cornification in the human fetal face. (A) Zygomatic skin. (B, G) Anterior nose near the external opening. (C, D) Lateral surface of the tongue. (E, F) Lower lip margin. (H, I) External auditory meatus. Panels (D), (F), $(\mathrm{G})$ and $(\mathrm{I})$ are higher magnification views of panels $(\mathrm{C}),(\mathrm{E}),(\mathrm{B})$, and $(\mathrm{H})$, respectively. The zygomatic skin $(\mathrm{A})$ is composed of an eosinophilic thin layer or stratum corneum (arrowheads) and the basal layer (stars) and, between them, the keratinocyte layer with a thickness of 2-3 cells. The basal cells are tall (stars) and a thick keratinocyte layer is evident (ker) with most nuclei remained in the nose (G), lip (F), and ear (I). In panel (F) (lip), the basal layer is cut obliquely or tangentially. In the ear, the basal cell nuclei are small in the anterior and medial aspects continuous with the developing tympanic membrane (open stars in panels $\mathrm{H}$ and I). In the lateral surface of the tongue, the basal layer provides multiple protrusions (arrows in panels $\mathrm{C}$ and D) into the deep mesenchymal tissue. NS, nasal septum. Scale bars $=0.1 \mathrm{~mm}(\mathrm{~A}, \mathrm{D}$, F, G, I), $1 \mathrm{~mm}$ (B, C, E, H). beneath the basal layer of the skin (Fig. 4F). In the external auditory meatus, a thin homogeneous lamina, that was nestin-negative, was seen beneath the basal layer (Fig. 4G).

\section{Observations of immunohistochemistry for glial fibrillary acidic protein or GFAP and desmin}

Positivity of desmin was seen in striated muscles at all sites (Fig. 5A-E). GFAP expression was restricted in cartilages 

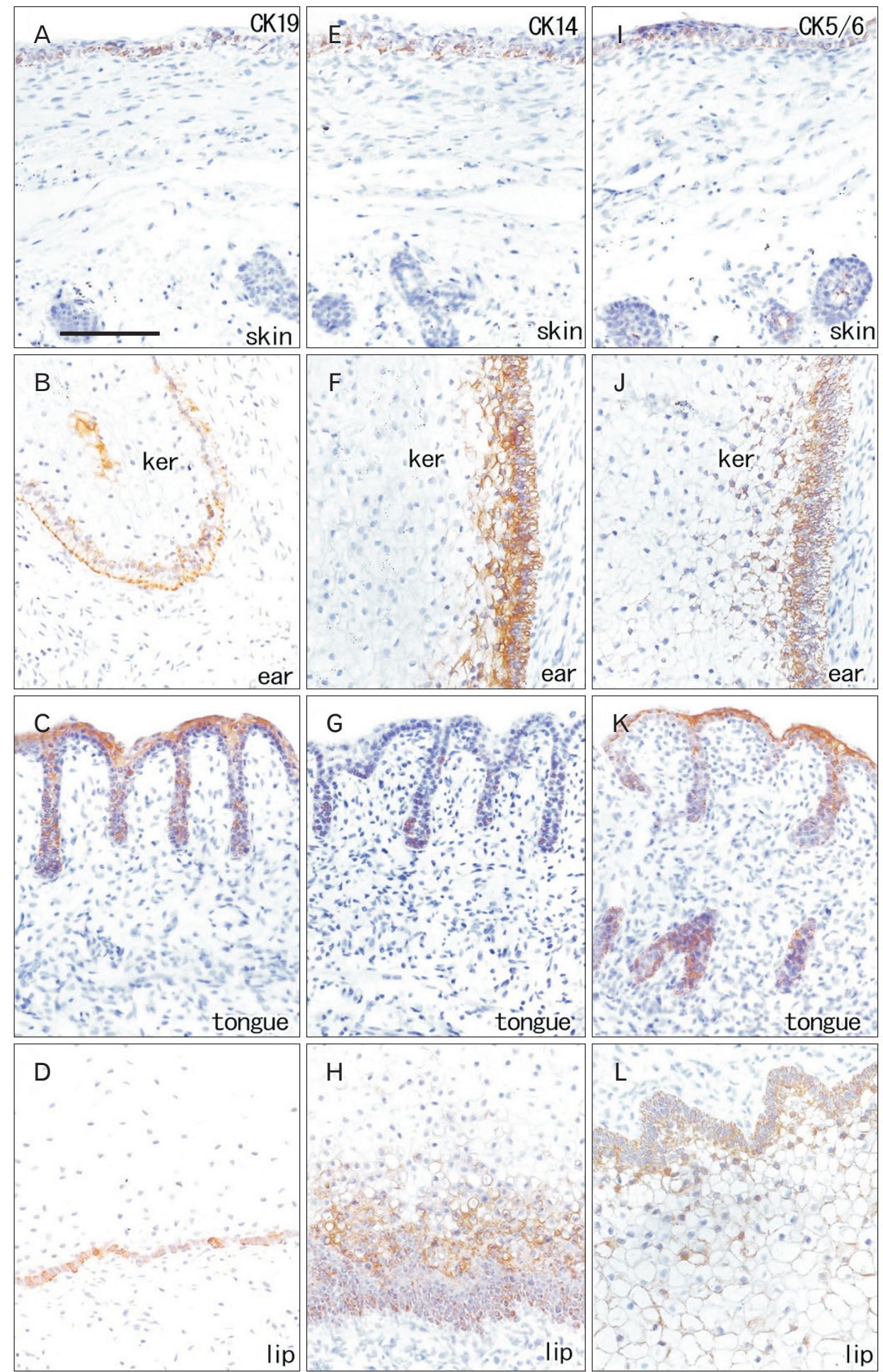
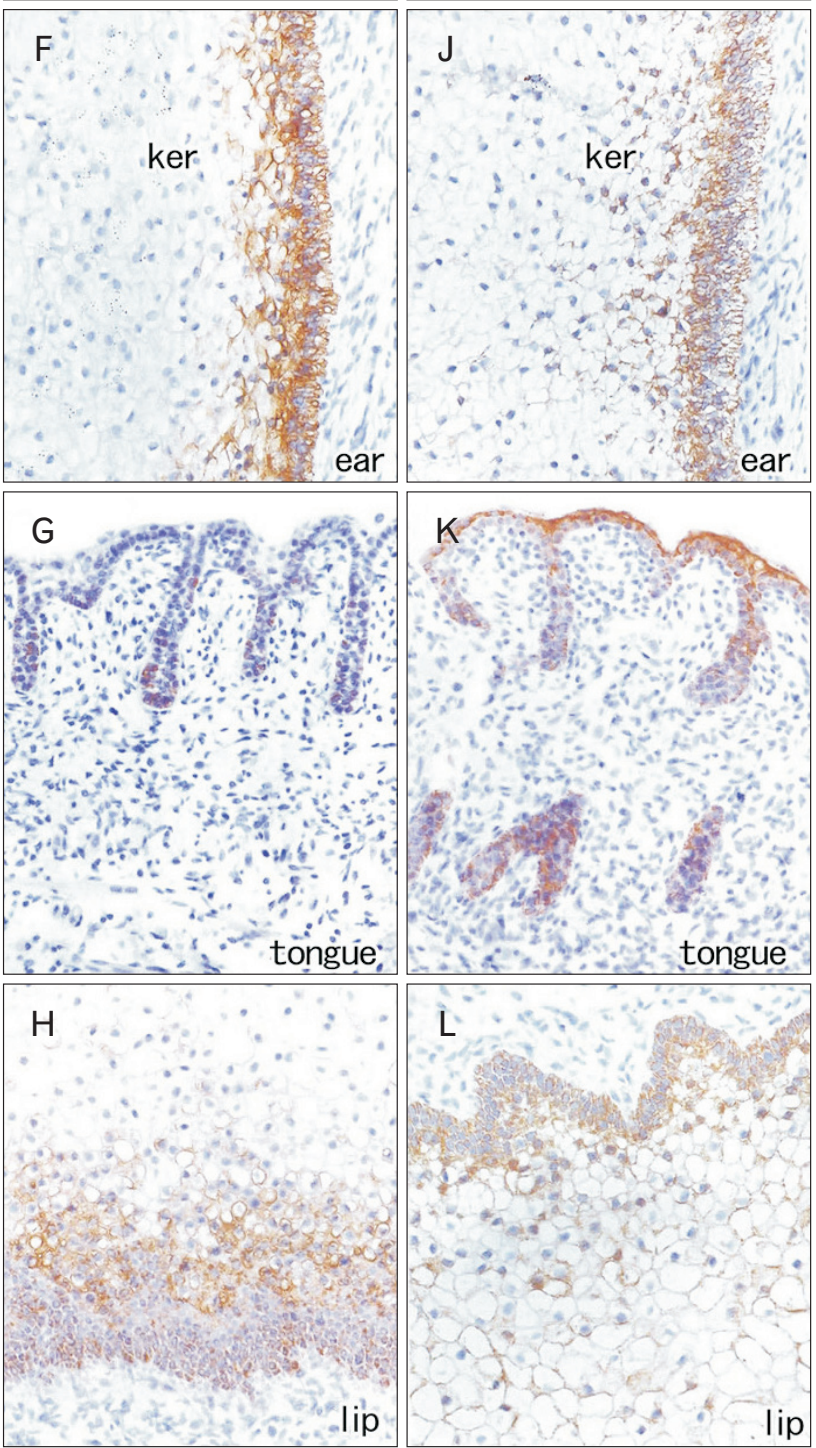

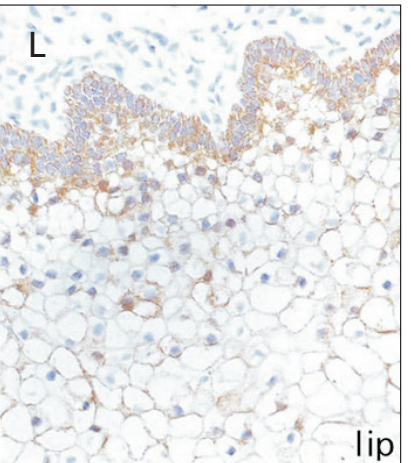

Fig. 2. Immunohistochemistry for cytokeratin (CK) 5/6, CK14, and CK19. Left-hand side column displays immunohistochemistry for CK19, the middle column shows that of CK14 and the right-hand column exhibits that of $\mathrm{CK} 5 / 6$. (A, E, I) Zygomatic skin (skin). (B, F, J) The external auditory meatus (ear). (C, G, $\mathrm{K})$ Lateral surface of the tongue (tongue). (D, H, L) The lower lip margin (lip). The panels of skin include a part of the parotid gland. Basal cells of all 4 sites are positive for all these 3 CKs. The parotid gland is also positive for CK19 but not for CK14 and CK5/6. All panels were prepared at the same magnification. Scale bar $=0.1 \mathrm{~mm}$ (A). along and around the external auditory meatus (Fig. 5G). The epidermis and epithelium contained no positive cells in these immunostainings.

\section{Observations of immunohistochemistry for proliferating cell nuclear antigen or PCNA}

The basal layer of the zygomatic skin often or sometimes expressed PCNA: almost half of basal cells were weakly positive, while one of every 10 cells were strongly positive 


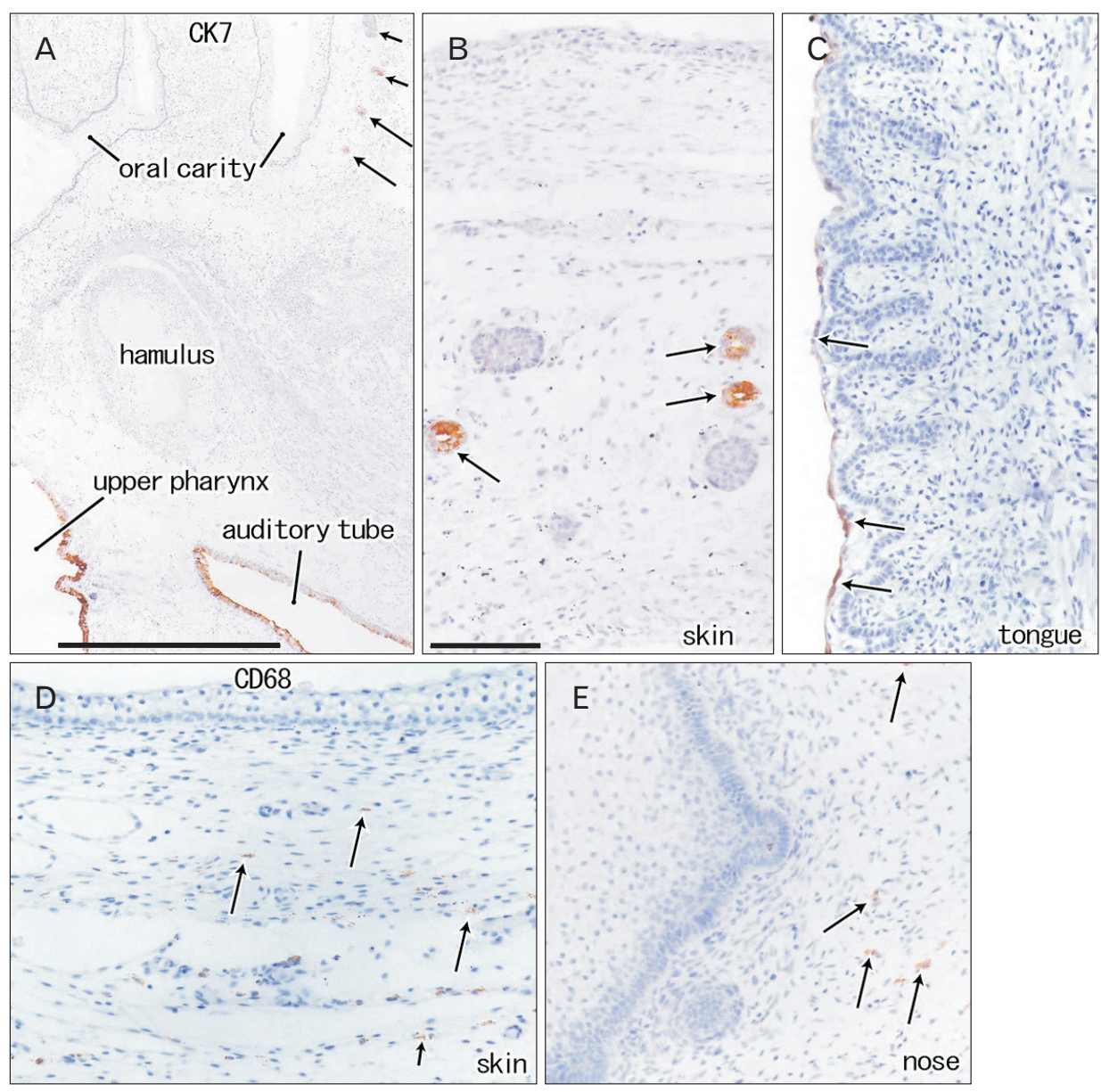

Fig. 3. Immunohistochemistry for cytokeratin (CK) 7 and CD68. Panels (AC) display immunohistochemistry for CK7, while panels (D) and (E) shows that of CD68. Panel (A) is a lower magnification view including the oral and pharyngeal cavities. Panels (B) and (D) display the zygomatic skin. Panel (C) and (E) exhibit the lingual epithelium and nasal plug, respectively. CK7 is positive in the upper pharynx and auditory tube (A) as well as in the salivary glands (arrows in panels $\mathrm{A}$ and B). A thin stratum corneum covering the lingual surface also expresses CK7 (C). The subcutaneous and subepithelial mesenchymal tissues contain CD68positive macrophages (arrows in panels $\mathrm{D}$ and $\mathrm{E}$ ), but the epithelium/epidermis including plug do not. Panels (B-E) were prepared at the same magnification. Scale bar $=1 \mathrm{~mm}(\mathrm{~A}), 0.1 \mathrm{~mm}(\mathrm{~B})$.
(Fig. 6A). The positive cells were likely to be adjacent in the basal layer. A thin, cornified layer of the skin contained a few positive cells. In the putative dermis and subcutaneous layer, the positive cells were scattered. Almost all basal cells at the external auditory meatus as well as all basal cells at the external nasal opening were strongly positive (Fig. 6B, C). Notably, in the plug, large keratinocytes in the basal two-third always contained PCNA-positive nucleus in the external nose and usually in the external ear (Fig. 6B, C). The deep protrusions of the basal layer of the lingual epithelium contained fewer positive cells than the primitive papilla (Fig. 6D). The lower lip margin contained several positive cells at the basal layer. Notably, near the basal layer of the lip, keratinocytes in the thick cornified layer carried PCNApositive nucleus (Fig. 6E).

\section{Observations of immunohistochemistry for CD34}

Mesenchymal and/or fibrous tissues beneath the zygomatic skin and along the external auditory meatus expressed CD34 much more strongly than mesenchymal tissues in the nose, tongue and lip when they were compared in the same section (Fig. 6F-J). The zygomatic skin carried a CD34-positive cell monolayer beneath the basal layer: the lamina appeared to be composed of cells and fibers (Fig. 6F). The external auditory meatus also carried the similar lamina but it was thin and weakly positive (Fig. 6G). We did not find the lamina in the external nasal opening, the lingual epithelium and the lower lip margin. In these 3 sites, CD34-positive structures were limited to vessels (Fig. $6 \mathrm{H}-\mathrm{J}$ ). The vessels reached the basal layer in the lip margin, but most of them did not enter into the papilla.

\section{Discussion}

First, we summarized the present results. A stratum corneum was evident in the zygomatic skin and lingual surface, but the latter was positive for CK7. Between the stratum basale and stratum corneum of the primitive skin, there was a simple intermediate layer comprising of 2-3 layered, large keratinocytes. This basic configuration was common in the 

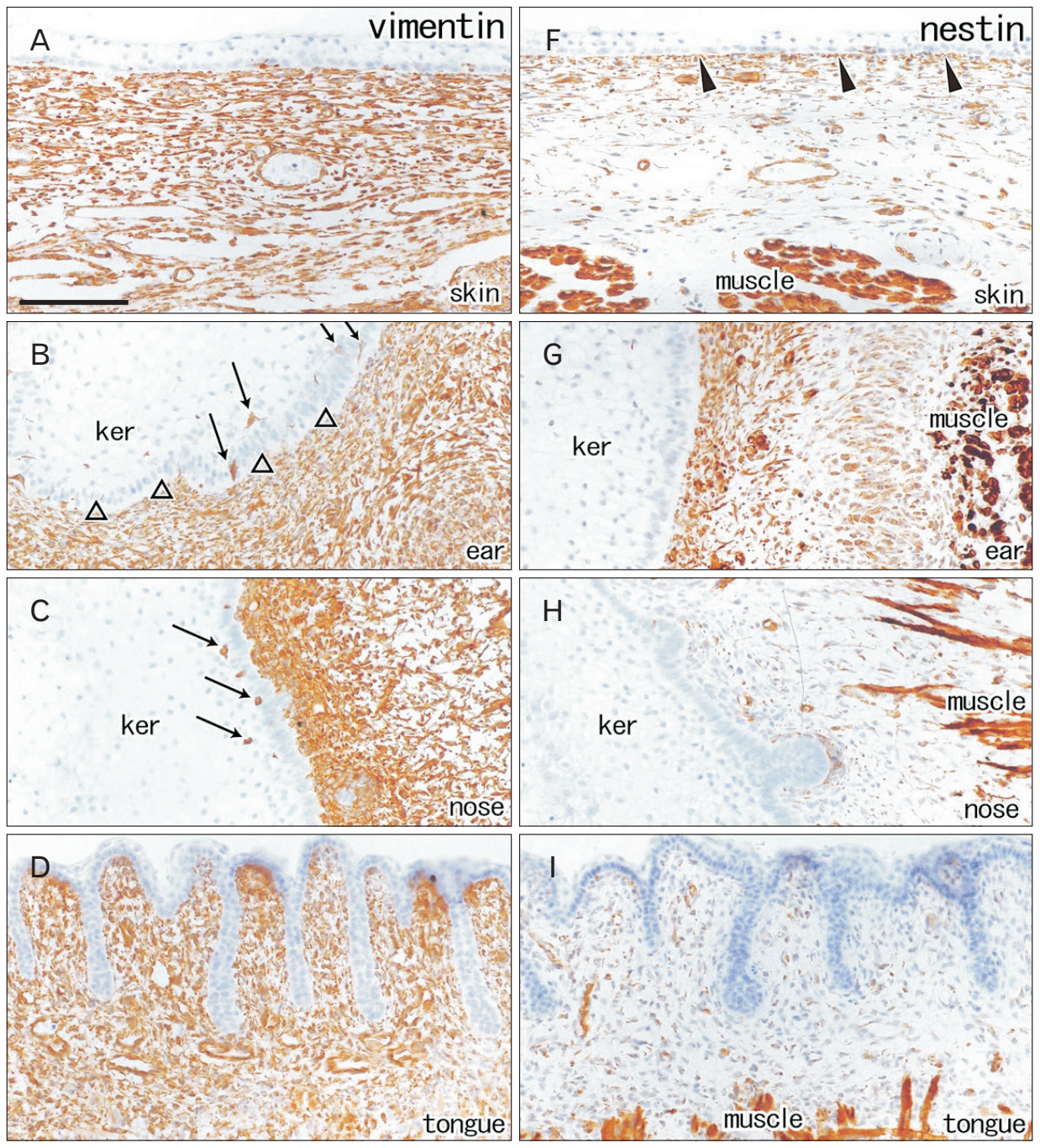

Fig. 4. Immunohistochemistry for vimentin and nestin. Left-hand side (or right-hand side) column displays immunohistochemistry for vimentin (or nestin). (A, F) The zygomatic skin. $(B, G)$ The external auditory meatus. (C, H) External nasal opening. (D, I) Lateral surface of the tongue. (E, J) The lower lip margin. Several vimentinpositive cells (arrows in panels B and C) are seen in the keratinocyte plug of the ear and nose (ker). A thin homogeneous lamina (triangles; vimentin-negative)
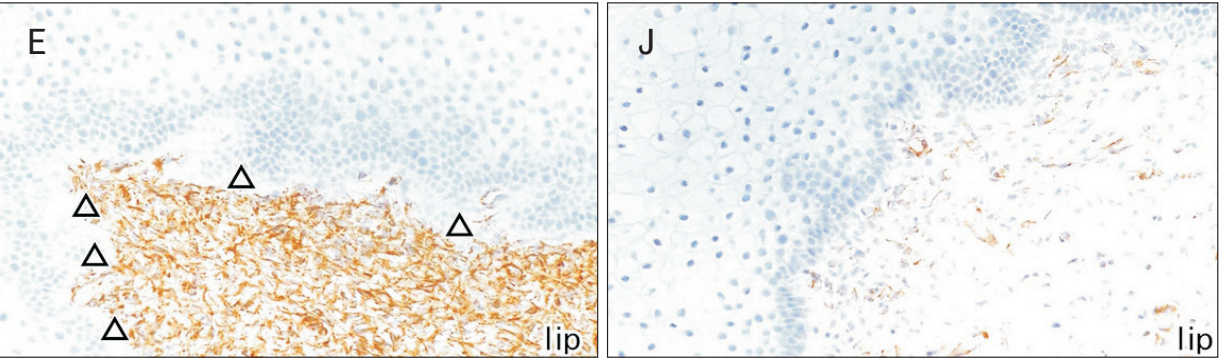
is evident beneath the basal layer of the epithelium of the ear and lip (B, E). Striated muscles exhibit nestin-reactivity strongly (F-I). Nestin-positive cells take a linear arrangement beneath the basal layer of the zygomatic skin (arrowheads in panel F). All panels were prepared at the same magnification. Scale bar $=0.1$ $\mathrm{mm}(\mathrm{A})$.

other 4 sites, but the intermediate, keratinocyte layer was much thicker than the zygomatic skin. A mesenchymal cell monolayer (nestin+, CD34+) was seen beneath the basal cells in the usual skin, but not in around the keratinocyte plug. Notably, in all 5 sites examined, all or most keratinocytes contained nucleus and, in the external ear and nose, they were positive for PCNA. Moreover, in the latter 2 sites, vimentinpositive mesenchymal cells appeared to migrate into the keratinocyte plug. The lingual epithelium was characterized by abundant, deep protrusions of the basal layer into the internal, mesenchymal tissue.

Keratin or CK is a well-known component of the epidermal and epithelial cells. However, to our knowledge, few study demonstrated the site-dependent difference in the fetal face: Shuler and Schwartz [32] carried the same question but antibodies were not defined at the date. In the present study, basal cells were always positive for CK19, 14, and 5/6 at any sites examined, but contrary to the skin, positivity of CK19 

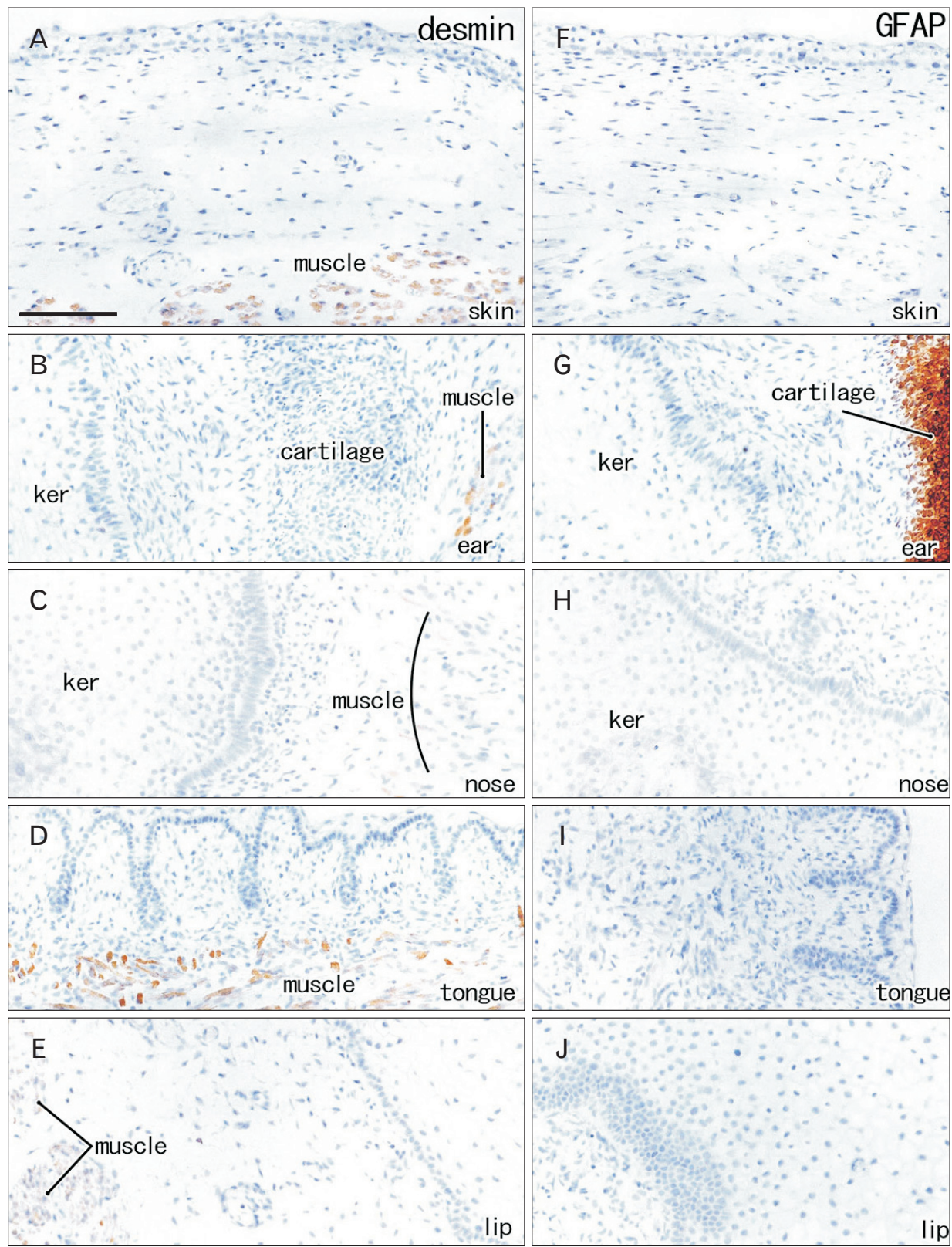

Fig. 5. Immunohistochemistry for desmin and glial fibrilary acidic protein. Left-hand side column displays immunohistochemistry for desmin, while right-hand side column exhibits that for glial fibrilary acidic protein (GFAP). (A, F) The zygomatic skin. $(B, G)$ The external auditory meatus. (C, H) External nasal opening. (D, I) Lateral surface of the tongue. (E, J) The lower lip margin. Striated muscles are desmin-positive (A-E). Elastic cartilage expresses GFAP along the external auditory meatus $(G)$. Keratinocyte plug (ker) as well as epidermis/epithelium contained no positive cells in these immunostainings. All panels were prepared at the same magnification. Scale bar $=0.1 \mathrm{~mm}(\mathrm{~A})$. was weaker than that of CK14 or CK5/6 in the keratinocyte plug at the external ear and nose. The lingual epithelium was also different from the skin: the CK14-positive cells were restricted in the deep protrusion and the stratum corneum expressed CK7. The lingual epithelium was characterized by abundant, deep protrusions of the basal layer into the internal, mesenchymal tissues. The strange expression of CK7 seemed not to connect with the lingual epithelium-specific differentiation such as the late maturation of keratinocytes as well as the early development of taste buds [33, 34]. CK9 expression is known in thick and hard cornification such as seen at the foot-sole [35], but thick keratinocyte layers at the fetal face might be different in differentiation and development.

The most striking finding in the present study seemed to be vimentin-positive mesenchymal cells scattering in the keratinocyte plug. This morphology suggested a superficial migration of mesenchymal cells and, between the migrating cell and large keratinocyte, an epitheliummesenchyme interaction might be maintained in the plug for the continuous proliferation of keratinocytes. Conversely, when the keratinocytes fills the luminal spaces of the anterior 

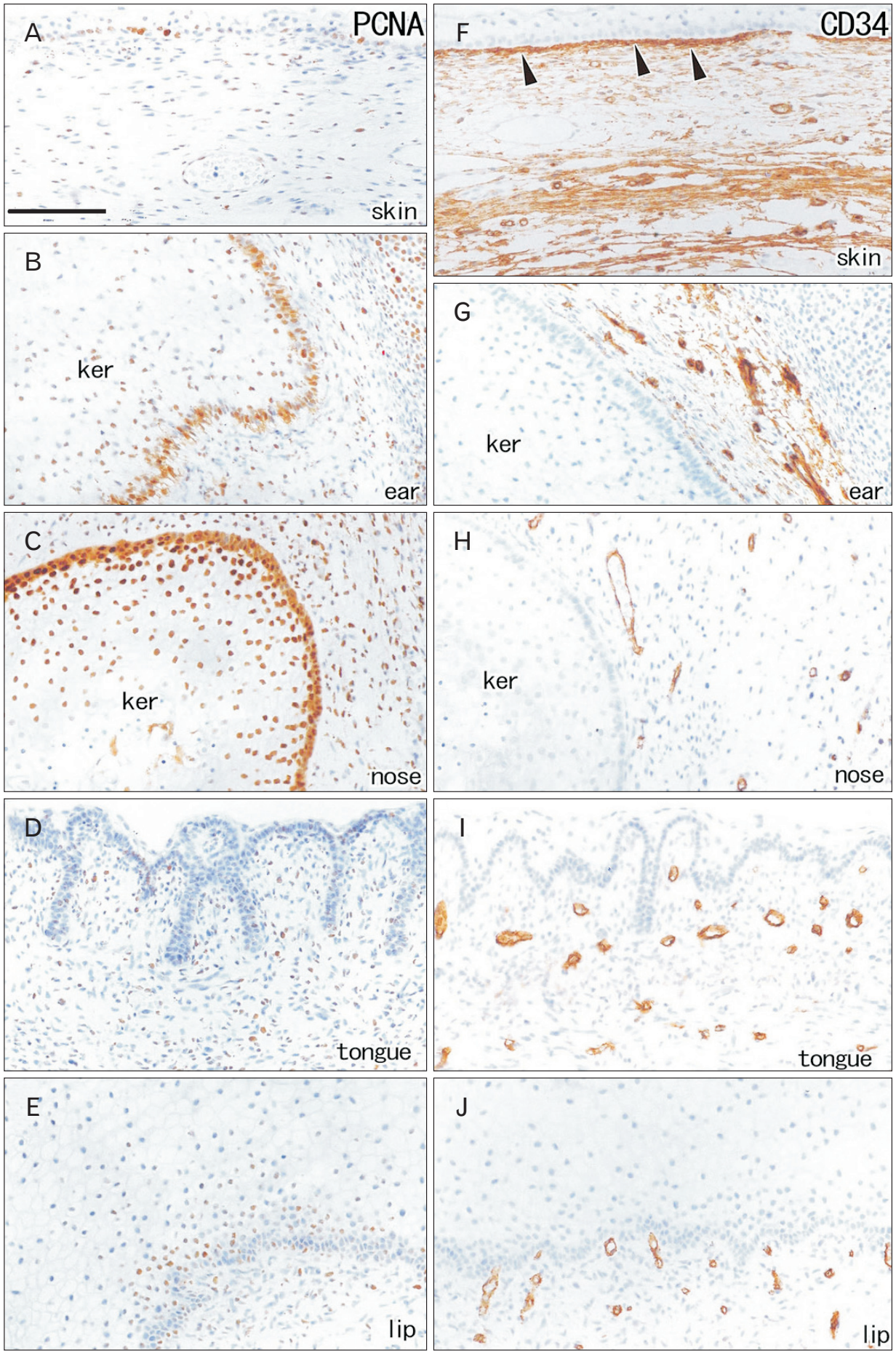

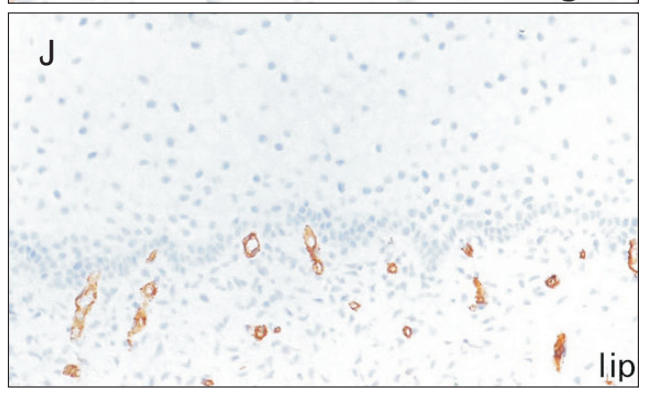

Fig. 6. Immunohistochemistry for proliferating cell nuclear antigen and CD34. Left-hand side column displays immunohistochemistry for proliferating cell nuclear antigen (PCNA), while right-hand side column exhibits that for CD34. (A, F) The zygomatic skin. (B, G) The external auditory meatus. (C, H) External nasal opening. (D, I) Lateral surface of the tongue. (E, J) The lower lip margin. The basal layers of the external ear and nose express PCNA strongly in contrast to the skin, tongue and lip. Moreover, in the plug, large keratinocytes near the basal layer contained PCNA-positive nucleus (B, C). Mesenchymal tissues beneath the zygomatic skin and along the external auditory meatus expressed CD34 much more strongly than other sites (panels $\mathrm{F}$ and J were taken from the same section). The zygomatic skin carried a CD34positive lamina beneath the basal layer (arrowheads in panel F). In the nose, tongue and lip (H-J), CD34-reactivity was limited to vessels. All panels were prepared at the same magnification. Scale bar $=0.1 \mathrm{~mm}(\mathrm{~A})$. nose and external auditory meatus completely, a pressure in the tissue was likely to increase to stop the superficial migration of vimentin-positive cells. A difference in the basal cell morphology was evident between the anterior and posterior aspects of the external auditory meatus: this fact might also suggest a contribution of the mesenchymal lining for determination of the epidermis. The tympanic cavity was adjacent to the anterior epidermis, while the posterior epidermis was surrounded by elastic cartilages. However, another interpretation seemed to be found in a difference in cell origin in external auditory epidermis [36]. In the lip margin, the amount of died and detached keratinocytes was 
likely to depend on the attaching area: the area seemed to be determined by the developing muscle mass in the lip. PCNA expression in the keratinocyte plug seems to be another striking feature. However, according to Scott et al. [37] and Onuma et al. [38], keratinocytes after final differentiation to cornification are likely to express PCNA. Therefore, in spite of the positivity of PCNA in the plug, some or most of the large keratinocytes were likely to lose proliferation activity. We needed to compare the results of PCNA staining with that of Ki67, but we had no residual unstained sections: this is a critical limitaion of this study.

No macrophages in the keratinocyte plug at the external ear and nose was one of the striking features. Because of no reaction of the keratinocyte plug found using deoxynucleotidyl transferase-mediated deoxyuridine triphosphate nick end-labeling method, Masumoto et al. [12] hypothesized a substance-P mediated cell death, but they themselves found that non-specific immunoreactivity was likely to bring their result. Cornification is a highly specific type of programmed cell death $[1,2]$. The epidermal differentiation does not involve the pro-apoptotic caspases, but is associated with caspase-14 induction and processing [39]. Conversely, to understand the plug formation, a major point seemed not to be found in cell death with caspase but proliferation. Does an epithelial mesenchymal interaction provide a clue for the continuous proliferation of keratinocytes in the plug? The suggested superficial migration of mesenchymal cells into the plug (see the paragraph above) might be a way of resolution. Likewise, a mesenchymal cell monolayer (nestin+, CD34+) was absent around the keratinocyte plug. In contrast, a thin homogeneous, vimentin-negative lamina was evident beneath the basal layer at the external ear and lip margin. This difference seemed to be also important but, without further information of matrix in the lamina, our discussion could not expand.

CD34-positive fibrous tissues were evident beneath the skin and along the external auditory meatus in contrast to the anterior nose, tongue and lip those expressed CD34 only in the vascular wall. This regionalization of CD34-positve tissues were consistent with that described by Abe et al. [31] and Katori et al. [30]. However, a mesenchymal cell monolayer (nestin+, CD34+) characterized the usual skin. Overall, loss of a mesenchymal monolayer as well as superficial migration of mesenchymal cells might connect with the specific differentiation of keratinocytes in the plug. Finally, a further study seems to be necessary for tight junction proteins in and around the keratinocyte plug since a similar plug in squamous cell carcinoma provided an evidence [40].

\section{Acknowledgements}

This study was supported by a grant (0620220-1) from the National R \& D Program for Cancer Control, Ministry of Health \& Welfare, Republic of Korea.

\section{References}

1. Mack JA, Anand S, Maytin EV. Proliferation and cornification during development of the mammalian epidermis. Birth Defects Res C Embryo Today 2005;75:314-29.

2. Mack JA, Li L, Sato N, Hascall VC, Maytin EV. Hoxb13 upregulates transglutaminase activity and drives terminal differentiation in an epidermal organotypic model. J Biol Chem 2005; 280:29904-11.

3. Warbrick JG. The early development of the nasal cavity and upper lip in the human embryo. J Anat 1960;94:351-62.

4. Nishimura Y. Embryological study of nasal cavity development in human embryos with reference to congenital nostril atresia. Acta Anat (Basel) 1993;147:140-4.

5. Kumoi T, Nishimura Y, Shiota K. The embryologic development of the human anterior nasal aperture. Acta Otolaryngol 1993; 113:93-7.

6. Anson BJ, Bast TH, Richany SF. The fetal and early postnatal development of the tympanic ring and related structures in man. Ann Otol Rhinol Laryngol 1955;64:802-23.

7. Nishimura Y, Kumoi T. The embryologic development of the human external auditory meatus. Preliminary report. Acta Otolaryngol 1992;112:496-503.

8. de la Cuadra-Blanco C, Peces-Peña MD, Jáñez-Escalada L, Mérida-Velasco JR. Morphogenesis of the human excretory lacrimal system. J Anat 2006;209:127-35.

9. Sevel D. Development and congenital abnormalities of the nasolacrimal apparatus. J Pediatr Ophthalmol Strabismus 1981; 18:13-9.

10. van der Werff JF, Nievelstein RA, Brands E, Luijsterburg AJ, Vermeij-Keers C. Normal development of the male anterior urethra. Teratology 2000;61:172-83.

11. van der Putte SC. The devlopment of the perineum in the human: a comprehensive histological study with a special reference to the role of the stromal components. Adv Anat Embryol Cell Biol 2005;177:1-131.

12. Masumoto H, Katori Y, Kawase T, Cho BH, Murakami G, Shibata S, Matsubara A. False positive reactivity of a substance P-antibody in the ectodermal/epithelial plug of the nose, ear, eye and perineum of the human and mouse fetuses. Okajimas Folia Anat Jpn 2010;87:33-40.

13. Franke WW, Grund C, Jackson BW, Illmensee K. Formation of cytoskeletal elements during mouse embryogenesis. IV. Ultra- 
structure of primary mesenchymal cells and their cell-cell interactions. Differentiation 1983;25:121-41.

14. Hay ED. Extracellular matrix, cell skeletons, and embryonic development. Am J Med Genet 1989;34:14-29.

15. Hendrix MJ, Seftor EA, Chu YW, Trevor KT, Seftor RE. Role of intermediate filaments in migration, invasion and metastasis. Cancer Metastasis Rev 1996;15:507-25.

16. Al Saleh S, Al Mulla F, Luqmani YA. Estrogen receptor silencing induces epithelial to mesenchymal transition in human breast cancer cells. PLoS One 2011;6:e20610.

17. Jain R, Fischer S, Serra S, Chetty R. The use of cytokeratin 19 (CK19) immunohistochemistry in lesions of the pancreas, gastrointestinal tract, and liver. Appl Immunohistochem Mol Morphol 2010;18:9-15.

18. Clark BZ, Beriwal S, Dabbs DJ, Bhargava R. Semiquantitative GATA-3 immunoreactivity in breast, bladder, gynecologic tract, and other cytokeratin 7-positive carcinomas. Am J Clin Pathol 2014;142:64-71.

19. Martins MD, Cavalcanti de Araujo V, Raitz R, Soares de Araujo $\mathrm{N}$. Expression of cytoskeletal proteins in developing human minor salivary glands. Eur J Oral Sci 2002;110:316-21.

20. Lourenco SV, Coutinho-Camillo CM, Buim ME, Uyekita SH, Soares FA. Human salivary gland branching morphogenesis: morphological localization of claudins and its parallel relation with developmental stages revealed by expression of cytoskeleton and secretion markers. Histochem Cell Biol 2007;128:361-9.

21. Galou M, Colucci-Guyon E, Ensergueix D, Ridet JL, Gimenez y Ribotta M, Privat A, Babinet C, Dupouey P. Disrupted glial fibrillary acidic protein network in astrocytes from vimentin knockout mice. J Cell Biol 1996;133:853-63.

22. Shibata S, Cho KH, Kim JH, Abe H, Murakami G, Cho BH. Expression of hyaluronan (hyaluronic acid) in the developing laminar architecture of the human fetal brain. Ann Anat 2013; 195:424-30.

23. Kim JH, Parkkila S, Shibata S, Fujimiya M, Murakami G, Cho $\mathrm{BH}$. Expression of carbonic anhydrase IX in human fetal joints, ligaments and tendons: a potential marker of mechanical stress in fetal development? Anat Cell Biol 2013;46:272-84.

24. Katori Y, Kawase T, Ho Cho K, Abe H, Rodríguez-Vázquez JF, Murakami G, Fujimiya M. Suprahyoid neck fascial configuration, especially in the posterior compartment of the parapharyngeal space: a histological study using late-stage human fetuses. Clin Anat 2013;26:204-12.

25. Abe S, Rhee SK, Osonoi M, Nakamura T, Cho BH, Murakami G, Ide Y. Expression of intermediate filaments at muscle insertions in human fetuses. J Anat 2010;217:167-73.

26. Yang Y, Makita T. Immunocytochemical colocalization of desmin and vimentin in human fetal skeletal muscle cells. Anat Rec 1996;246:64-70.

27. Kopher RA, Penchev VR, Islam MS, Hill KL, Khosla S, Kaufman DS. Human embryonic stem cell-derived CD34+ cells function as MSC progenitor cells. Bone 2010;47:718-28.

28. Lin CS, Xin ZC, Deng CH, Ning H, Lin G, Lue TF. Defining adipose tissue-derived stem cells in tissue and in culture. Histol Histopathol 2010;25:807-15.

29. Young HE, Steele TA, Bray RA, Hudson J, Floyd JA, Hawkins K, Thomas K, Austin T, Edwards C, Cuzzourt J, Duenzl M, Lucas PA, Black AC Jr. Human reserve pluripotent mesenchymal stem cells are present in the connective tissues of skeletal muscle and dermis derived from fetal, adult, and geriatric donors. Anat Rec 2001; 264:51-62.

30. Katori Y, Kiyokawa H, Kawase T, Murakami G, Cho BH. CD34-positive primitive vessels and other structures in human fetuses: an immunohistochemical study. Acta Otolaryngol 2011;131:1086-90.

31. Abe S, Suzuki M, Cho KH, Murakami G, Cho BH, Ide Y. CD34positive developing vessels and other structures in human fetuses: an immunohistochemical study. Surg Radiol Anat 2011;33:919-27.

32. Shuler CF, Schwartz SA. Embryogenesis of stratified squamous epithelium. I. Tissue-specific expression of keratin proteins. Exp Cell Biol 1986;54:301-9.

33. Sawaf MH, Shabana AH, Pelissier A, Forest N, Ouhayoun JP. Characterization of cytokeratin patterns in the developing human tongue. Int J Dev Biol 1991;35:91-100.

34. Iwasaki S, Aoyagi H, Yoshizawa H. Localization of keratins 13 and 14 in the lingual mucosa of rats during the morphogenesis of circumvallate papillae. Acta Histochem 2011;113:395-401.

35. Moll I, Heid H, Franke WW, Moll R. Distribution of a special subset of keratinocytes characterized by the expression of cytokeratin 9 in adult and fetal human epidermis of various body sites. Differentiation 1987;33:254-65.

36. Michaels L, Soucek S. Development of the stratified squamous epithelium of the human tympanic membrane and external canal: the origin of auditory epithelial migration. Am J Anat 1989;184:334-44.

37. Scott RJ, Hall PA, Haldane JS, van Noorden S, Price Y, Lane DP, Wright NA. A comparison of immunohistochemical markers of cell proliferation with experimentally determined growth fraction. J Pathol 1991;165:173-8.

38. Onuma H, Mastui C, Morohashi M. Quantitative analysis of the proliferation of epidermal cells using a human skin organ culture system and the effect of DbcAMP using markers of proliferation (BrdU, Ki-67, PCNA). Arch Dermatol Res 2001;293:133-8.

39. Lippens S, Kockx M, Knaapen M, Mortier L, Polakowska R, Verheyen A, Garmyn M, Zwijsen A, Formstecher P, Huylebroeck D, Vandenabeele P, Declercq W. Epidermal differentiation does not involve the pro-apoptotic executioner caspases, but is associated with caspase-14 induction and processing. Cell Death Differ 2000;7:1218-24.

40. Langbein L, Pape UF, Grund C, Kuhn C, Praetzel S, Moll I, Moll $\mathrm{R}$, Franke WW. Tight junction-related structures in the absence of a lumen: occludin, claudins and tight junction plaque proteins in densely packed cell formations of stratified epithelia and squamous cell carcinomas. Eur J Cell Biol 2003;82:385-400. 